\title{
Avaliação do consumo de tiossulfato em diferentes suportes para biofiltros percoladores visando a biodessulfurização de biogás
}

\author{
L. F. HIDALGO ${ }^{1, a}$, J. L. SANTOS ${ }^{2}$, S. P. TAYAR ${ }^{1}$, M. C. PALMIERI ${ }^{1}$ e D. BEVILAQUA ${ }^{1}$ \\ ${ }^{1}$ Universidade Estadual Paulista - Instituto de Química - UNESP Araraquara \\ ${ }^{2}$ Universidade de São Paulo - Instituto de Química - USP São Carlos \\ E-mail para contato: ${ }^{a}$ leticia.ferraresi@gmail.com
}

\begin{abstract}
RESUMO - O biogás é uma fonte de energia renovável que pode ser utilizada para produzir calor e energia, em substituição aos combustíveis fósseis. Um fator que limita sua utilização é a quantidade de contaminantes em sua composição, sendo o $\mathrm{H}_{2} \mathrm{~S}$ o contaminante mais comum do biogás. A utilização de biofiltros percoladores tem se mostrado promissora na eliminação deste contaminante e a seleção de um meio suporte ideal é um passo importante para a operação deste processo, visto influenciar no desenvolvimento do biofilme e, consequentemente, na biodegradação dos contaminantes. A necessidade de suportes baratos e duráveis para o crescimento e acúmulo da biomassa é um desafio para biofiltros em escala real. Este trabalho estudou o consumo de tiossulfato em diferentes concentrações por microrganismos oxidantes de enxofre obtidos a partir de lodo anaeróbio em colunas preenchidas com Policloreto de Polivinila (PVC), Polietileno Tereftalato (PET) e Politetrafluoretileno $\left(\right.$ Teflon $\left.^{\circledR}\right)$, comparados à espuma de poro aberto de Poliuretano (OPP). Apesar dos distintos valores de área superficial, os materiais testados foram promissores na utilização em biofiltros percoladores nas condições de operação desse trabalho, pois apresentaram resultados muito semelhantes ao OPP já conhecido pela sua eficiência na biodessulfurização de biogás.
\end{abstract}

\section{INTRODUÇÃO}

O biogás é uma fonte energética renovável, sustentável e pouco prejudicial ao meio ambiente. Constituído em grande parte por metano, a sua combustão permite converter energia química em calor ou eletricidade devido ao alto poder calorífico desse composto, sendo a qualidade do biogás essencial para esse processo, tanto em porcentagem de metano quanto em pureza (WELLAND, 2010; ZHOU et al., 2015).

O principal fator que limita a utilização do biogás é a quantidade de $\mathrm{H}_{2} \mathrm{~S}$ em sua composição. Além de ser tóxico e inflamável, sua presença é prejudicial para os equipamentos de conversão de energia, sendo necessário removê-lo tanto por razões operacionais do sistema de produção, quanto por razões ambientais e de segurança (JIN et al., 2005; ZIEMIŃSKI et al., 2016). O biofiltro percolador é uma das tecnologias biológicas utilizadas para a descontaminação de uma corrente gasosa, no qual o efluente gasoso passa por um meio suporte inerte, úmido e poroso onde uma comunidade microbiana está imobilizada e é capaz de usar os contaminantes como fonte de energia, fazendo a descontaminação do gás (SOLCIA et al., 2014). 
A seleção de suportes baratos e duráveis é um passo importante para a biodessulfurização, visto ser um fator que influencia no desenvolvimento do biofilme e, consequentemente, na biodegradação dos contaminantes. Neste contexto, o presente trabalho estudou o consumo de substrato tiossulfato por microrganismos oxidantes de enxofre obtidos a partir de lodo anaeróbio e inoculados em colunas em escala de laboratório, sendo estas preenchidas com diferentes suportes, visando à futura aplicação para o processo de biodessulfurização.

\section{MATERIAS E MÉTODOS}

Como meios suportes inertes para a imobilização dos microrganismos, foram utilizadas tiras de Cloreto de Polivinil (PVC), Polietileno Tereftalato (PET), Politetrafluoroetileno $\left(\right.$ Teflon ${ }^{\circledR}$ ) e espuma de poro aberto de poliuretano (OPP), como apresentados na Figura 1. As alternativas testadas são materiais duráveis e de baixo valor agregado que constituem resíduo industrial e foram comparadas ao OPP, um suporte já utilizado na literatura por Fernández et al. (2014), Solcia et al. (2014) e Zhou et al. (2015).

Figura 1 - a) PVC em tiras, b) PET em tiras, c) Resíduo de Teflon ${ }^{\circledR}$ em torno, d) OPP.

a)

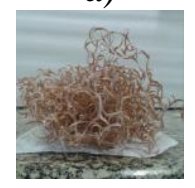

b)

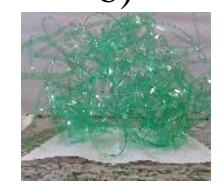

c)

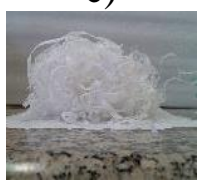

d)

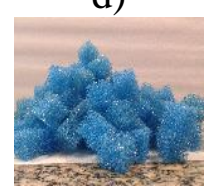

Para a simulação de biofiltros percoladores, foram utilizadas quatro colunas de vidro de $40 \mathrm{~cm}$ de comprimento e $6 \mathrm{~cm}$ de diâmetro, com $28 \mathrm{~cm}$ de altura ocupada pelos meios suportes, conforme apresentado na Figura 2.

Figura 2 - Colunas com função de biofiltros percoladores.

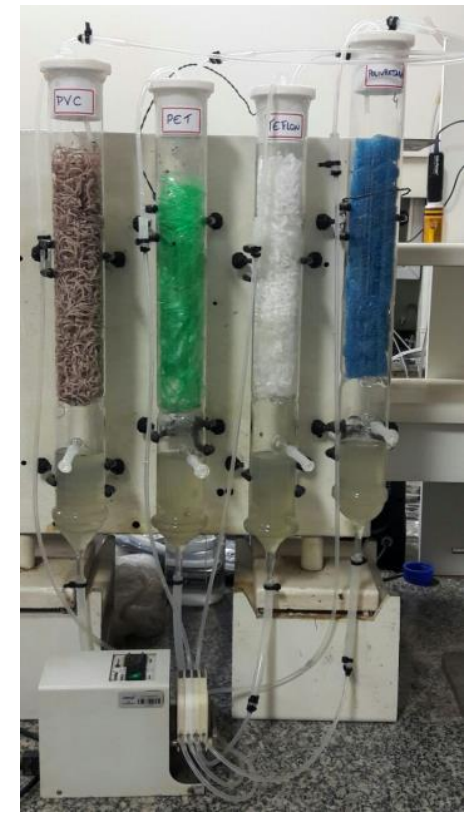


Utilizaram-se duas concentrações de tiossulfato $\left(2,5\right.$ e 5,0 $\mathrm{g} \mathrm{L}^{-1}$ de $\left.\mathrm{Na}_{2} \mathrm{~S}_{2} \mathrm{O}_{3}\right)$ como fonte de enxofre e, no início de cada período, as colunas foram inoculadas com solução contendo $50 \%$ de meio de cultura (DSMZ 113) e 50\% de inoculo, obtido por centrifugação do lodo anaeróbio da Estação de Tratamento de Esgoto do Matão, São Paulo, Brasil. Após o esgotamento do tiossulfato, retirou-se $50 \%$ da solução percolada e adicionou-se então meio DSMZ 113 fresco, realizando 8 ciclos.

Durante todo o período de operação, as colunas foram envolvidas com papel alumínio para impedir a entrada de luz no sistema, simulando o comportamento de biofiltros em escalas industriais e, dessa forma, impedir a oxidação dos compostos reduzidos de enxofre por bactérias fotoheterotróficas e microalgas. Os valores de $\mathrm{pH}$ das soluções percoladoras de cada coluna foram mantidos em 7 e a temperatura em $35^{\circ} \mathrm{C}$. Para induzir condições anóxicas, uma corrente de argônio foi passada por cada coluna no início da operação e nas substituições de meio de cultivo. A circulação da solução nas quatro colunas foi realizada por uma bomba peristáltica de quatro canais (Ismatec Reglo MS-4/8), utilizando a mesma vazão para ambas $\left(500 \mathrm{~mL} \cdot \mathrm{h}^{-1}\right)$.

A concentração de tiossulfato foi monitorizada por iodometria (RODIER, 1998), a de sulfato por turbidimetria, a de nitrato por espectrofotometria UV e a de nitrito por espectrofotometria de N- (1-naftil) -etileno diamina (CLESCERL et al., 1989).

\section{RESULTADOS E DISCUSSÕES}

Por meio da quantificação de tiossulfato e sulfato na solução percolada de cada coluna, conforme apresentado na Figura 3, observou-se que o comportamento no consumo do substrato foi semelhante nos 4 materiais suportes analisados, o que significa que as três alternativas consideradas (PVC, PET e Teflon ${ }^{\circledR}$ ) são comparáveis com o OPP.

Figura 3 - Concentração de $\mathrm{S}_{-} \mathrm{S}_{2} \mathrm{O}_{3}{ }^{2-}$ e S-SO ${ }_{4}{ }^{2-} \mathrm{em} \mathrm{g} \mathrm{m}^{-3}$ nos biofiltros percoladores utilizando diferentes meios suportes para as concentrações iniciais de $\mathrm{Na}_{2} \mathrm{~S}_{2} \mathrm{O}_{3}$ igual a 2,5 g.L $\mathrm{L}^{-1}\left(1^{\circ}\right.$

período) e $5,0 \mathrm{~g} . \mathrm{L}^{-1}$ ( $2^{\circ}$ período).

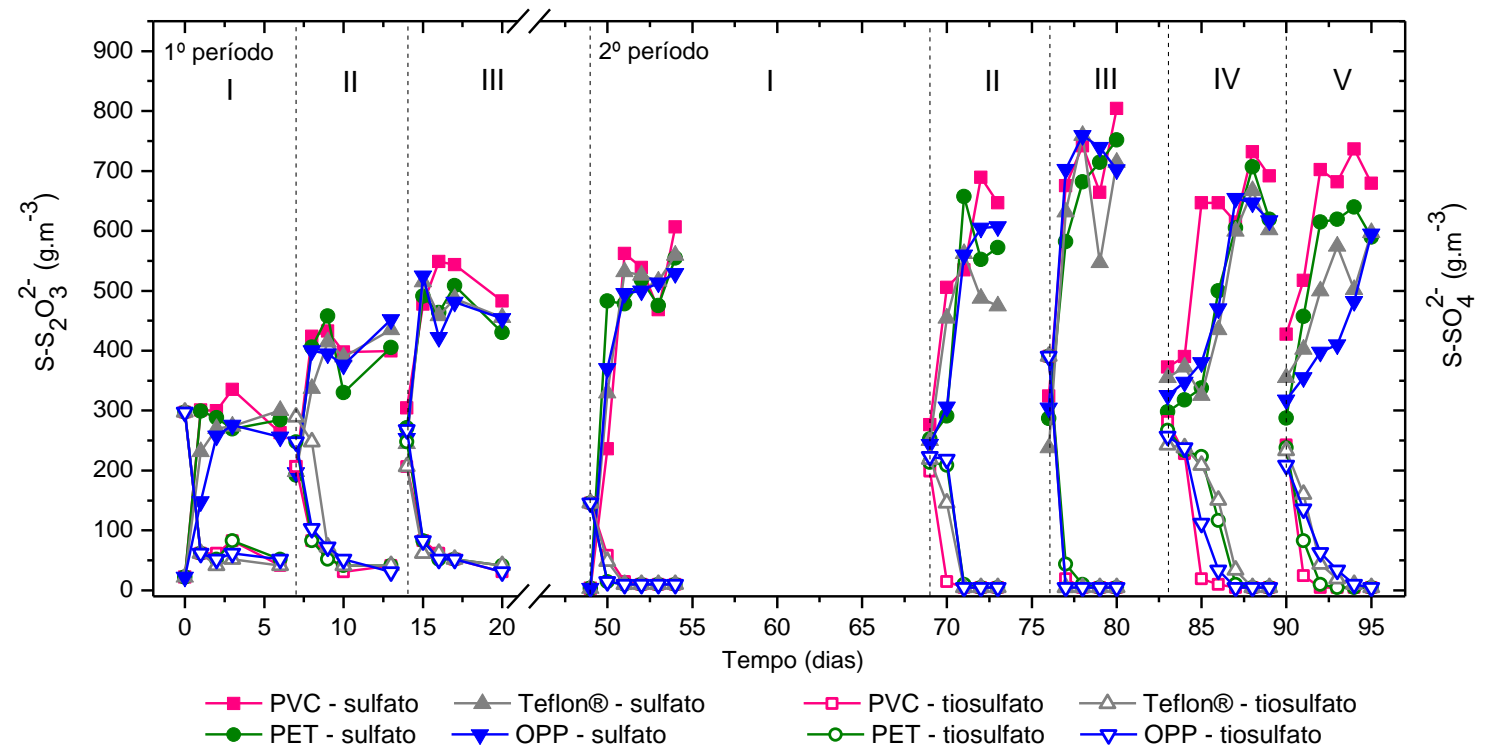


O aumento da concentração de sulfato ocorreu durante os períodos de diminuição da concentração de tiossulfato para os quatro suportes analisados, o que é explicado pela reação de oxidação do tiossulfato a sulfato pelo consórcio de microrganismos desnitrificantes imobilizados nos suportes de cada coluna. No início do experimento a concentração inicial de sulfato foi baixa pois não fazia parte do meio de cultivo e as concentrações deste íon no início de cada ciclo foram maiores pois apenas $50 \%$ do meio de cultura foi trocado.

As quantificações de nitrato e nitrito na solução percolada de cada coluna, conforme apresentado na Figura 4, mostraram que a concentração de nitrato foi reduzida principalmente nos primeiros dias de cada ciclo, o que corresponde ao período de consumo de tiossulfato. Além disso, ocorre acumulação de nitrato na solução de percolação das quatro colunas, o que pode ser justificado pelo uso de outros compostos como aceptores finais de elétrons, como o oxigênio dissolvido na solução de percolação.

Figura 4 - Concentração de $\mathrm{S}_{-} \mathrm{S}_{2} \mathrm{O}_{3}{ }^{2-}$ e S-SO $\mathrm{SO}_{4}{ }^{2-} \mathrm{em} \mathrm{g} \mathrm{m}^{-3}$ nos biofiltros percoladores utilizando diferentes meios suportes para as concentrações iniciais de $\mathrm{Na}_{2} \mathrm{~S}_{2} \mathrm{O}_{3}$ igual a 2,5 g.L $\mathrm{L}^{-1}\left(1^{\circ}\right.$ período) e $5,0 \mathrm{~g} . \mathrm{L}^{-1}$ ( $2^{\circ}$ período).

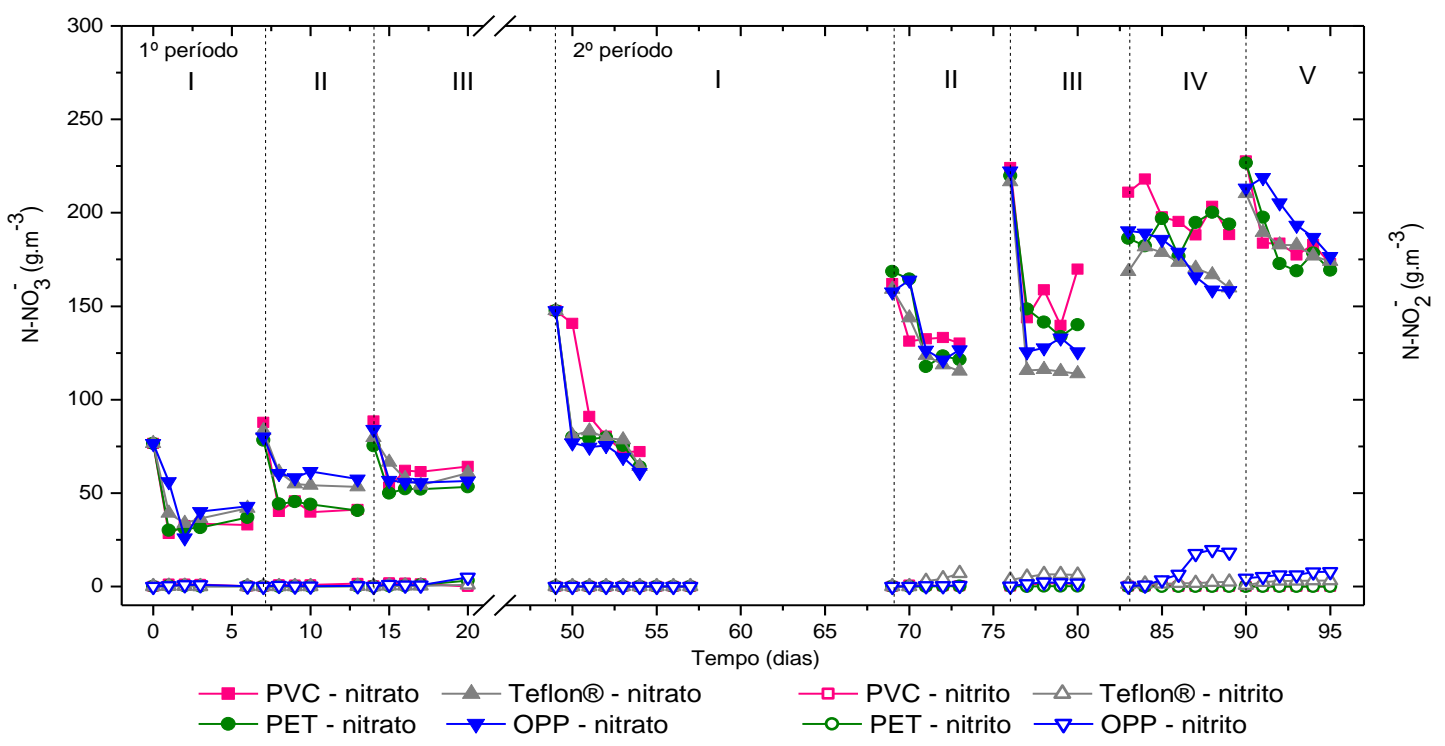

Foi possível observar que houve uma baixa conversão de nitrato a nitrito pelo sistema, sendo o valor de sua concentração constante e próxima de zero para os três suportes em todos os ciclos. Isso pode ser explicado pela complexa composição microbiológica do lodo utilizado, que também pode conter microrganismos que utilizam o nitrito como aceptor final de elétrons e produzem nitrogênio gasoso, mantendo sempre baixa sua concentração em solução.

Os materiais suportes foram submetidos à análise para determinação da área superficial segundo técnica baseada na teoria de Brunauer, Emmett e Teller (BET) e os valores obtidos foram: PVC $0,432 \mathrm{~m}^{2} / \mathrm{g}$, PET $0,443 \mathrm{~m}^{2} / \mathrm{g}$, Teflon ${ }^{\circledR} 0,909 \mathrm{~m}^{2} / \mathrm{g}$ e OPP $6,694 \mathrm{~m}^{2} / \mathrm{g}$. Apesar do OPP apresentar maior área superficial que os demais suportes testados, este parâmetro não foi determinante para os resultados obtidos no monitoramento das colunas nas condições de 
operação utilizadas nesse trabalho, visto que as colunas preenchidas com PVC, PET e Teflon ${ }^{\circledR}$ apresentaram comportamento semelhante ao OPP quanto ao consumo de substrato.

Nas imagens obtidas por microscopia eletrônica de varredura com emissão de campo (FEG) apresentadas na Figura 5 foi possível observar a superfície de cada material suporte antes do experimento (primeira linha) e o biofilme desenvolvido após 130 dias de monitoramento (segunda linha). Os biofilmes formados puderam ser observados em todos os materiais suportes e foram predominantemente compostos de bactérias cocobacilares de tamanhos variados, mostrando que os microrganismos responsáveis pelo tratamento podem aderir em polímeros de baixo custo e de polaridades diferentes.

Figura 5 - Imagens de microscopia eletrônica de varredura (FEG) de suportes de PVC, PET, Teflon e OPP (primeira linha) e dos biofilmes desenvolvidos após 95 dias de experimento (segunda linha).

PVC
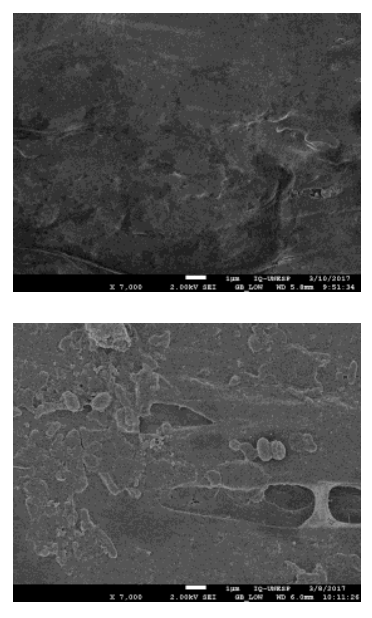

PET
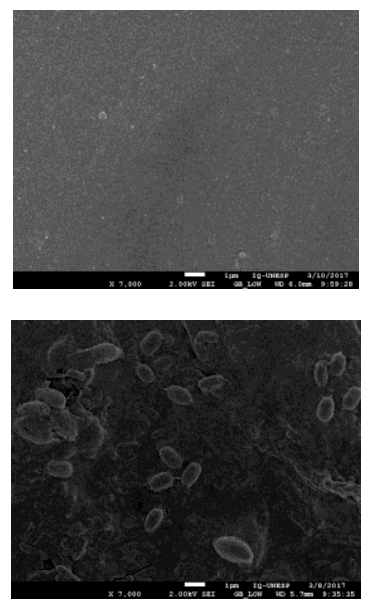

Teflon $^{\circledR}$
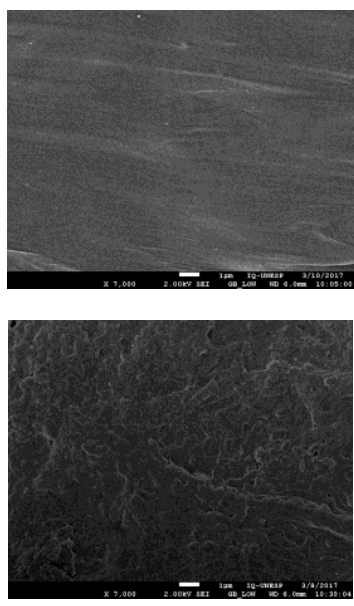

OPP
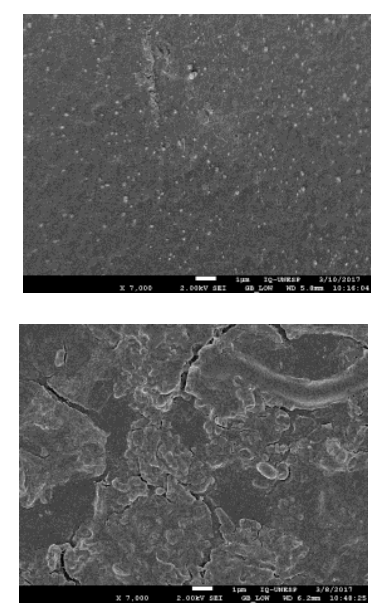

\section{CONCLUSÃO}

A quantificação de tiossulfato, sulfato, nitrato e nitrito mostrou que os materiais testados (PVC, PET e Teflon ${ }^{\circledR}$ ) são promissores e apresentaram eficiência semelhante à espuma de poro aberto de poliuretano quanto ao consumo de substrato em biofiltros percoladores.

Além disso, embora o OPP tenha apresentado maior área superficial que os demais suportes testados, este parâmetro não foi determinante para os resultados do monitoramento nas condições operacionais utilizadas neste trabalho, uma vez que os suportes testados apresentaram comportamento semelhante ao OPP durante todo o monitoramento.

Quanto ao biofilme formado nos materiais suporte, observou-se que os microrganismos responsáveis pelo tratamento podem aderir em polímeros de baixo custo e polaridade diferente, além de uma predominância de bactérias cocobacilares. 


\section{AGRADECIMENTOS}

Agradecimentos a FAPESP pela bolsa de Iniciação Científica (Processo: 2015/249905), a CAPES, a CNPq (472375/2012-1) e ao LMA-IQ pela disponibilidade de utilização FEGSEM.

\section{REFERÊNCIAS}

CLESCERI, L. S.; GREENBERG, A. E.; TRUSSEL, R. R. Standards methods for examination of water and wastewater. 17th ed. Washington: APHA/ AWWA/ WPCF, 1989.

FERNÁNDEZ, M. et al. Biogas biodesulfurization in an anoxic biotrickling filter packed with open-pore polyurethane foam. J. Hazard. Mater., v. 264, p. 529-535, 2014.

JIN, Y.; VEIGA, M. C.; KENNES, C.; Autotrophic deodorization of hydrogen sulfide in a biotrickling filter. J. Chem. Technol. Biotechnol., v. 80, p. 998-1004, 2005.

RODIER, J. Análisis de las aguas. Barcelona: Omega, 1998.

SOLCIA, R. B.; RAMÍREZ, M.; FERNÁNDEZ, M.; CANTERO, D.; BEVILAQUA, D.; Hydrogen sulphide removal from air by biotrickling filter using open-pore polyurethane foam as a carrier. Biochem. Eng. J., v. 84, p. 1-8, 2014.

WELlAND, P. Biogas production: current state and perspectives. Appl. Microbiol. Biotechnol., v. 85, n. 4, p. 849 - 860, 2010.

ZIEMIŃSKI, K.; KOPYCKI, W. J.; Impact of different packing materials on hydrogen sulfide biooxidation in biofilters installed in the industrial environment. Energy \& Fuels (ACS Publications), 30 (11), pp 9386-9395, 2016.

ZHOU, Q.; LIANG, H.; YANG, S.; JIANG, X.; The removal of hydrogen sulfide from biogas in a microaerobic biotrickling filter using polypropylene carrier as packing material. Appl. Biochem. Biotechnol., v. 175, p. 3763-3777, 2015. 